\title{
A FINITE ELEMENT APPROACH TO DEVELOP TRACK GEOMETRICAL IRREGULARITY THRESHOLDS FROM THE SAFETY ASPECT
}

\author{
AMin Miri \\ School of Civil Engineering, Sharif University of Technology, Tehran, Iran \\ e-mail: amin.miri.iust@gmail.com \\ Saeed Mohammadzadeh, Hoda SAleK \\ School of Railway Engineering, Iran University of Science and Technology, Tehran
}

\begin{abstract}
Riding quality and safety of rail tracks are directly influenced by track geometry; hence, their degradation along time could reduce safety and cause serious accidents. Standards propose thresholds for track geometrical parameters to keep track safety and riding comfort at an acceptable level. In this study, a method is proposed to select or define a set of proper thresholds for geometrical parameter irregularities according to desirable to safety level. The impact of track geometry irregularities on the derailment index has been investigated through the finite element model. The results suggest that twist and gauge shortage have a greater effect on the derailment index compared to the vertical profile of the track. Having the critical values of geometrical irregularities that result in derailment, safety factors of Iranian and Euro code standards in determining their thresholds are calculated and compared. It is shown that each standard has a unique set of safety factors that depend on speed and geometrical parameters.
\end{abstract}

Keywords: maintenance and inspection, track geometry parameters, finite element, Adams/rail software

\section{Notations}

$\begin{array}{ll}Q, Y & - \text { vertical and lateral forces between rail and wheel flange, respectively } \\ \beta & - \text { contact angle of rail and wheel flange } \\ \mu & - \text { coefficient of friction between rail and wheel flange } \\ Z & - \text { alignment of modeled track } \\ X & - \text { longitudinal coordinate of modeled tracks } \\ I & - \text { alignment irregularity value } \\ m_{o}, m_{b}, m_{w} & - \text { mass of car body, bolster and wheel set, respectively } \\ I_{o x}, I_{o y}, I_{o z} & - \text { inertia of car body around } x, y \text { and } z \text { axis, respectively } \\ I_{w x}, I_{w y}, I_{w z} & - \text { inertia of wheel set around } x, y \text { and } z \text { axis, respectively } \\ K_{P V}, K_{S V} & - \text { primary and secondary vertical dampers stiffness, respectively } \\ K_{L S} & - \text { lateral dampers stiffness }\end{array}$

\section{Introduction}

Safety and ride comfort are two important characteristics of any railway network. These characteristics are closely related to the geometrical condition of track superstructure, meaning whenever the track superstructure is at standard condition, so are the safety and ride comfort of passing trains. To monitor geometrical conditions of railway tracks, track quality indexes are proposed that are based on track geometrical irregularities. 
Whether a geometrical parameter is considered irregular or normal, it is assessed through comparing the measured geometrical parameter with the pre-determined set of thresholds proposed in standard guidelines and standards. Table 1 presents the geometrical parameter threshold as stated in Iranian guideline and Euro code standard (Alert limit state) (Iran Ministry of Roads and Transportation, 2005; EN-13848-5, 2008). It is clear from Table 1 that for a certain geometrical parameter at a certain speed, each guideline proposes different threshold values due to different operational regime and characteristics of the networks in which they are applied.

Table 1. Iran and Euro-code thresholds (all values in $\mathrm{mm}$ )

\begin{tabular}{|c|c|c|c|c|c|c|c|}
\hline$V>230$ & $200<V<230$ & $160<V<200$ & $120<V<160$ & $80<V<120$ & $V<80$ & $\begin{array}{l}\text { Speed } \\
{[\mathrm{km} / \mathrm{h}]}\end{array}$ & $\begin{array}{c}\text { Track } \\
\text { parameter }\end{array}$ \\
\hline 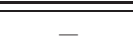 & 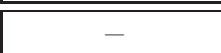 & $\overline{\overline{12}}$ & $\overline{16}$ & $\overline{16}$ & $\overline{18}$ & Iran & \multirow{2}{*}{$\begin{array}{c}\text { Vertical } \\
\text { profile }\end{array}$} \\
\hline 16 & 20 & 20 & 23 & 26 & 28 & Euro code & \\
\hline- & - & 6 & 8 & 10 & 12 & Iran & \multirow{2}{*}{ Gauge + } \\
\hline 28 & 28 & 28 & 35 & 35 & 35 & Euro code & \\
\hline- & - & 2 & 2 & 2 & 2 & Iran & \multirow{2}{*}{ Gauge - } \\
\hline 5 & 7 & 7 & 10 & 11 & 11 & Euro code & \\
\hline- & - & 5 & 5 & 5 & 5 & Iran & \multirow{2}{*}{ Alignment } \\
\hline 10 & 12 & 12 & 14 & 17 & 22 & Euro code & \\
\hline- & - & 1.5 & 1.5 & 1.5 & 1.5 & Iran & \multirow{2}{*}{ Twist } \\
\hline 5 & 7 & 7 & 7 & 7 & 7 & Euro code & \\
\hline
\end{tabular}

The point to keep in mind regarding the thresholds is that maintenance operations are dependent upon them. So proposing restricted values for thresholds would result in frequent maintenance operations and higher maintenance expenditures, while loose thresholds may increase the possibility of accidents due to excessive irregularities. In this regard, developing an optimized set of thresholds would not only reduce expenses, but also guarantee safety of the operation.

Although defining thresholds of track geometrical irregularities seems to be of great importance, the focus of studies is rather on track geometrical parameters. Some papers have proposed novel track quality indexes based on track geometrical parameters (Madejski and Grabczyk, 2002; ORE, 1981; Miri and Mohammadzadeh, 2014). Others studied the effect of track geometrical irregularities on the performance and conditional assessment of the track, such as initiation and evolution of rail corrugation (Jin et al., 2005), effects of maintenance operations on track quality (Ataei et al., 2014), proposing an inspection interval for track geometrical parameters (Arasteh Khouy et al., 2013), and evaluating the probability of derailment (Mohammadzadeh et al., 2011). Also, there are emerging technologies such as the performance-based track geometry inspection system that relate geometrical parameters of track to vehicle performance in real time (Li et al., 2006). In a recent study by Arasteh Khouy et al. (2014) a cost model is proposed to specify the cost-effective maintenance limits for track geometry maintenance. The model considers degradation rates of different track sections and takes into account the costs associated with inspection, tamping, delay time penalties and risk of accidents due to poor track quality to come up with the cost-effective intervention limit of the longitudinal level for tamping.

The aim of this paper is to propose a method that could be used to develop a set of track geometrical irregularity thresholds from the safety point of view. Track geometrical parameters considered in this paper include vertical profile, alignment, track gauge, cross level (also known as "cant") and twist, which are schematically presented in Fig. 1. To measure safety of proposed thresholds for each track geometrical parameter, the derailment index is considered as the safety indicator. 
(a)

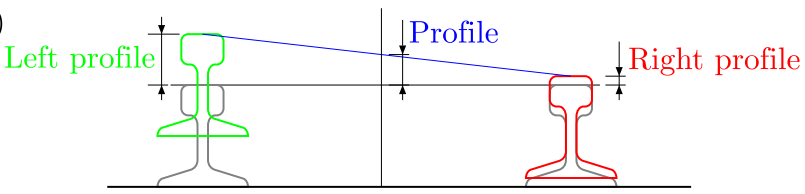

(b)

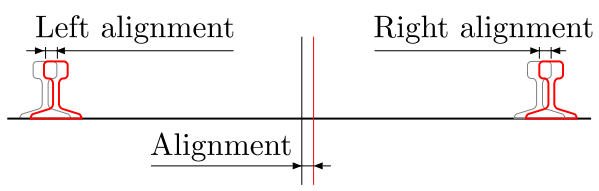

(c)

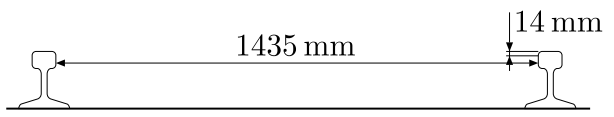

(d)

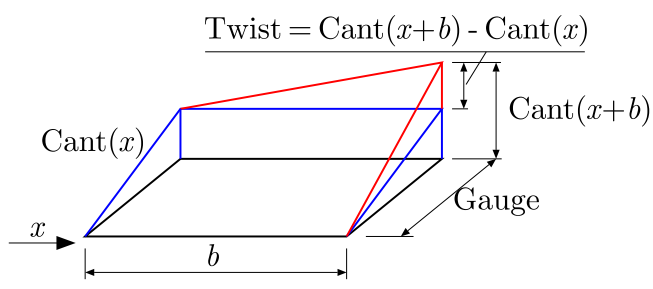

Fig. 1. (a) Vertical profile, (b) alignment, (c) gauge, (d) cant and twist irregularities

Derailment occurs when car wheels run off the rail that supplies support and guidance of the vehicle. Many papers have been published concerning this subject since it is crucial to railway safety (Yadav, 2007; Wu and Wilson, 2006; Elkins and Wu, 2000; Nadal, 1908; Weinstock, 1984; Karmel and Sweet, 1981). Derailment is divided into two main categories: sudden derailment and flange climbing derailment, of which the second category is taken into account in this study.

Flange climb derailment is the case in which wheels climb to the top of the rail individually and then run over it. In this condition, forces causing derailment are higher than resisting forces, but not powerful enough to cause the first case (Yadav, 2007). Such derailment occurs as vertical forces tend to decrease or as a result of increasing lateral forces which are combined with the forwarding movement of the vehicle. In the case of the vertical profile, the vertical forces $Q$ would decrease and as a result, $Y / Q$ increases and may reach the critical limit. This case is also known as "unloading".

There are different theories in the field of the derailment phenomenon such as Nadal theory (Nadal, 1908), Weinstocks (Weinstock, 1984) and Kereszty (Yadav, 2007). According to Nadal (1908), if the resisting forces are higher than the derailing forces, no derailment will occur. Therefore, by analyzing forces applied to the flange - according to the condition stated above it could be concluded that

$$
\mu(Y \sin \beta+Q \cos \beta)+Y \cos \beta \leqslant Q \sin \beta
$$

which could be restated as

$$
\frac{Y}{Q} \leqslant \frac{\tan \beta-\mu}{1+\mu \tan \beta}
$$

in which $Y$ and $Q$ are the lateral and vertical forces between the rail and wheel flange, respectively. $\beta$ is the contact angle of the rail and wheel flange and $\mu$ is the coefficient of friction between the flange and rail. For most wheel types, $\beta$ is equal to $68^{\circ}$ (Yadav, 2007). Also depending on 
the geometry and roughness of contact surface, $\mu$ varies between 0.25 and 0.27 (Yadav, 2007). Using these values, equation (1.2) simplifies as

$$
\frac{Y}{Q} \leqslant 1.4
$$

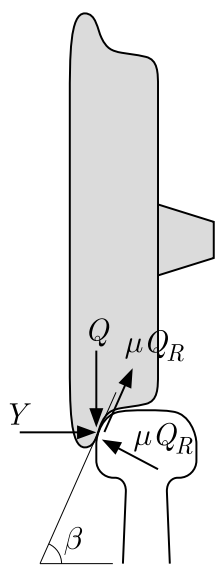

Fig. 2. Free-body diagram of wheel-rail contact forces

Considering the simplicity and comprehensiveness of Nadal theory, it is used as derailment theory in this study. Different values have been stated as the critical limit of the $Y / Q$ ratio. According to UIC 518 and EN14363, in tracks with curve radii of more than 250 meters, the $Y / Q$ ratio shall not be greater than 0.8 according to the sliding mean over $2 \mathrm{~m}$ of the track. Also, 0.8 has been stated as the critical value for $Y / Q$ ratio in various works (Elkins and $\mathrm{Wu}$, 2000; Karmel and Sweet, 1981; Kik et al., 2002). In this regard, the critical value of the $Y / Q$ ratio is considered to be 0.8 throughout the paper.

Another important factor in developing thresholds of geometrical irregularities is the chord length. Most guidelines and standards consider chord lengths of 10, 19, and 37 meters. Throughout this paper, a 10 meter chord is selected to control short wavelength defects that can result in high wheel forces over a short portion of the track. These forces may not produce excessive car body motion yet their action on the wheels and track may cause derailment, which is in line with the purpose of this paper.

\section{Methodology of research}

The aim of this paper is to find the amplitude of track geometrical irregularities that result in derailment. To do so, tracks with a length of 100 meters are modeled in Adams/Rail. Solid elements are used to model the track, and the space between each sleeper is divided into two distinct elements. Geometrical defects are simulated based on the definition of track geometrical parameters using mathematical functions which are characterized by wavelength and amplitude and applied to a 10 meter chord of the modeled tracks.

Next, a freight wagon (characteristics of the wagon are presented in Table 2) passes over the modeled track with a geometrical defect, and dynamic analyses are carried out to determine lateral and vertical forces. Hence, the derailment index is determined for a certain amplitude of geometrical irregularity. Next, the amplitude of geometrical irregularity is increased and the whole process repeats until the derailment index reaches the critical threshold of 0.8 ; so the corresponding amplitude of geometrical irregularity that results in derailment is determined. Since the speed is an effective parameter in the derailment phenomenon, the whole process is carried out for speeds of 40,80 , and $120 \mathrm{~km} / \mathrm{h}$. 
Table 2. Characteristics of freight wagon used in simulations

\begin{tabular}{|c|c|c|c|}
\hline Symbols & Values & Unit & Name \\
\hline \hline$m_{o}$ & 32000 & $\mathrm{~kg}$ & mass of car body \\
\hline$m_{b}$ & 1503 & $\mathrm{~kg}$ & mass of a bolster \\
\hline$m_{w}$ & 1503 & $\mathrm{~kg}$ & mass of wheel set \\
\hline$I_{o x}$ & $5.68 \cdot 10^{4}$ & $\mathrm{~kg} \mathrm{~m}^{2}$ & inertia of car body around $x$ axis \\
\hline$I_{o y}$ & $1.97 \cdot 10^{6}$ & $\mathrm{~kg} \mathrm{~m}^{2}$ & inertia of car body around $y$ axis \\
\hline$I_{o z}$ & $1.97 \cdot 10^{6}$ & $\mathrm{~kg} \mathrm{~m}^{2}$ & inertia of car body around $z$ axis \\
\hline$I_{w x}$ & 810 & $\mathrm{~kg} \mathrm{~m}^{2}$ & inertia of wheel set around $x$ axis \\
\hline$I_{w y}$ & 810 & $\mathrm{~kg} \mathrm{~m}^{2}$ & inertia of wheel set around $y$ axis \\
\hline$I_{w z}$ & 112 & $\mathrm{~kg} \mathrm{~m}{ }^{2}$ & inertia of wheel set around $z$ axis \\
\hline$K_{P V}$ & 6 & $\mathrm{MN} / \mathrm{m}$ & primary vertical dampers stiffness \\
\hline$K_{S V}$ & 6 & $\mathrm{MN} / \mathrm{m}$ & secondary vertical dampers stiffness \\
\hline$K_{L S}$ & 6 & $\mathrm{MN} / \mathrm{m}$ & lateral dampers stiffness \\
\hline
\end{tabular}

\section{Investigating the effects of alignment}

The alignment of the track increases lateral forces on the rail which, according to Nadal theory, could result in derailment if the irregularity is high enough. A polynomial function of the 4th order is chosen to model the alignment, which is as follows

$$
z=x^{4}-2 l x^{3}+l^{2} x^{2}
$$

in which $z$ is the alignment of the modeled track, $x$ is the longitudinal coordinate of the modeled track, and $l$ is the alignment irregularity value. Figure 3 shows a $12 \mathrm{~mm}$ left rail alignment in a 100 meters track that starts from the point at 50 meters and continues up to the point at 60 meters. Dynamic analysis for this track is carried out and Fig. 4 demonstrates the results of the front axle of front and rear bogies, at a speed of $80 \mathrm{~km} / \mathrm{h}$.

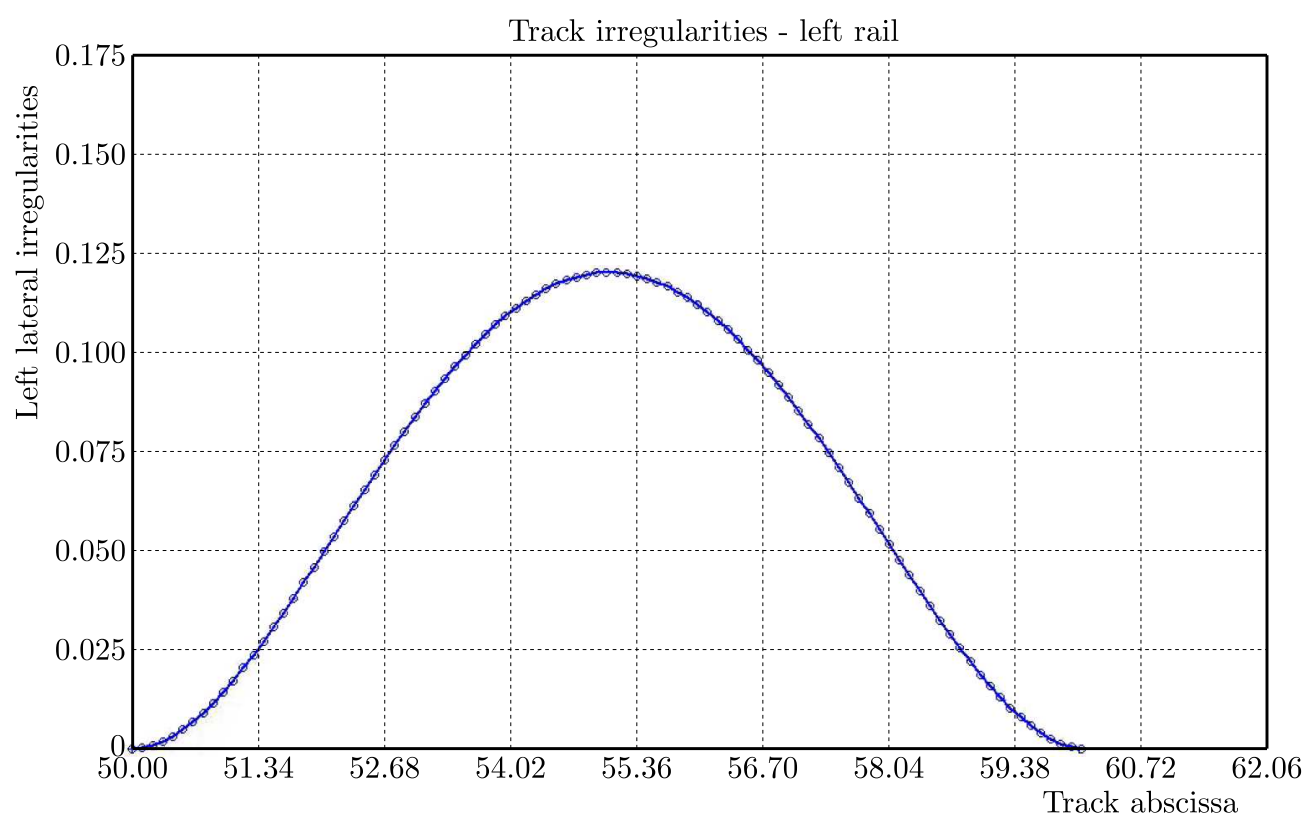

Fig. 3. Model of the alignment defect 

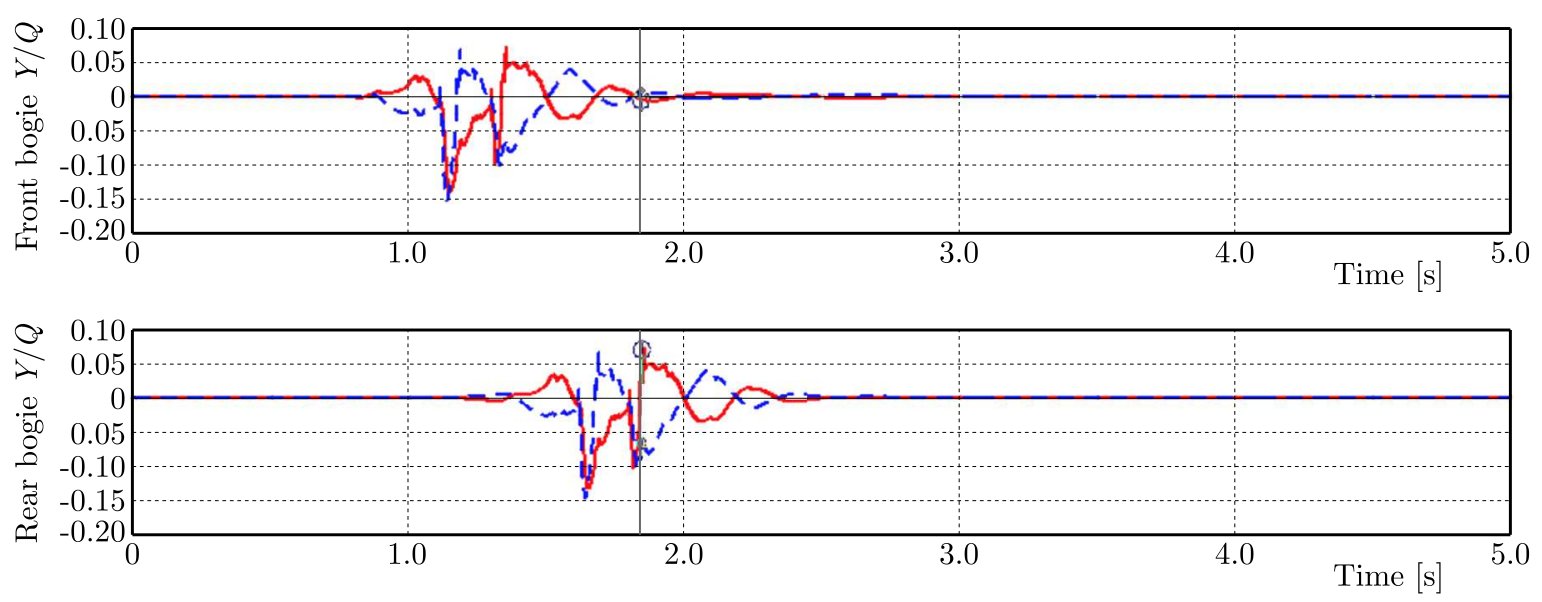

Fig. 4. Result of dynamical analysis of the modeled track with the alignment defect in Adams rail

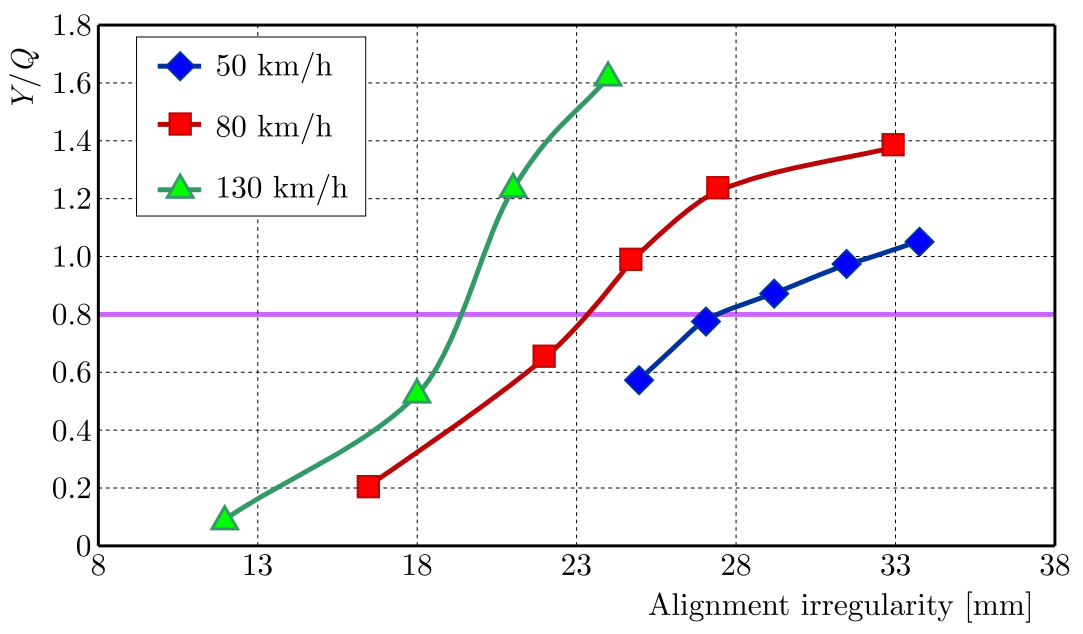

Fig. 5. Derailment index $(Y / Q)$ versus alignment irregularity for speeds of 50, 80, and $140 \mathrm{~km} / \mathrm{h}$

Figure 5 presents the results of dynamic analyses of tracks with the alignment defect for speeds of 50,80 , and $140 \mathrm{~km} / \mathrm{h}$. It is evident that as train speed increases, derailment occurs at lower wavelengths of the alignment defect. For speeds of 50, 80, and $140 \mathrm{~km} / \mathrm{h}$, derailment occurs at alignment irregularities of 27,21, and 18, respectively. These values are close to the thresholds stated in Euro code standard, but considerably higher than those stated in Iranian standard.

\section{Investigating the effects of the vertical profile}

Vertical forces of the wheel on the rail could decrease in the presence of the vertical profile irregularity which increases the $Y / Q$ value and could result in derailment. The vertical profile is modeled using the same geometrical function used to model the alignment defect. The results of dynamic analysis are presented in Fig. 6 . In a lower speed of $50 \mathrm{~km} / \mathrm{h}$, the derailment ratio remains below the critical value of 0.8 for vertical profiles of up to $350 \mathrm{~mm}$. But at $140 \mathrm{~km} / \mathrm{h}$, derailment occurs at a vertical profile irregularity of $40 \mathrm{~mm}$. Generally, it could be seen that the derailment ratio is less sensitive to the vertical profile than to the alignment, since $Y / Q$ remains fairly below the critical value for higher vertical profile irregularities. 


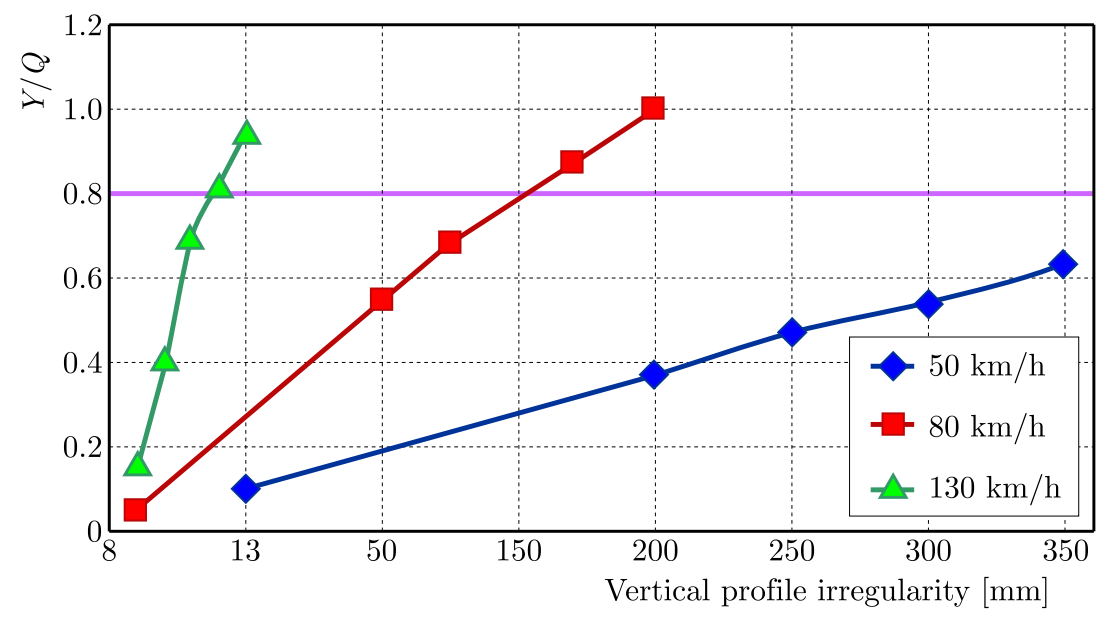

Fig. 6. Derailment index versus vertical profile irregularity for speeds of 50, 80, and $140 \mathrm{~km} / \mathrm{h}$

\section{Investigating the effects of the track gauge}

Track gauge variations can lead to large lateral wheel forces resulting in derailment. Both extra and shortage of the gauge are undesirable, since an extra gauge may end up in wheels falling off the rail, while shortage of gauge could result in wheels climbing on the top of the rail. A trapezoidal function is used to model extra and shortage of the track gauge, as shown in Fig. 7 . Figures $8 \mathrm{a}$ and $8 \mathrm{~b}$ present the results of dynamical analysis for the modeled tracks with extra and shortage of the gauge, respectively.

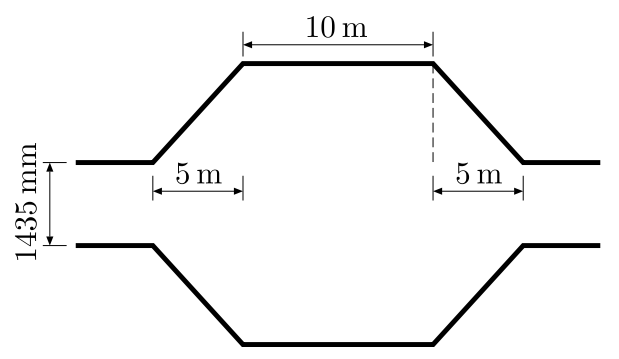

Fig. 7. Geometrical function used to model track gauge irregularities

(a)

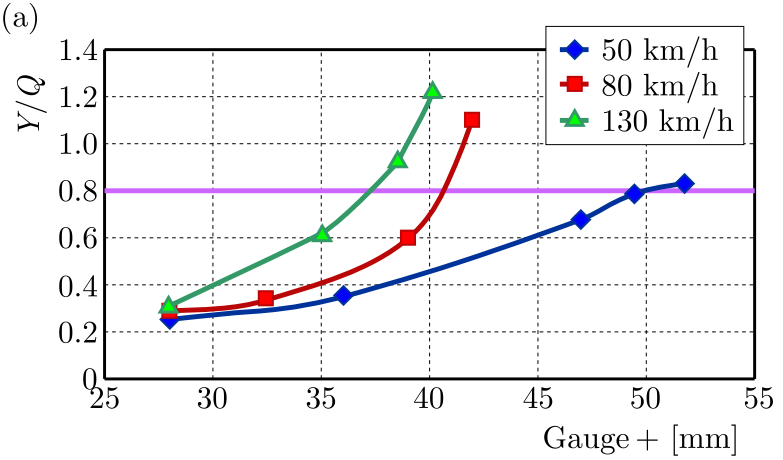

(b)

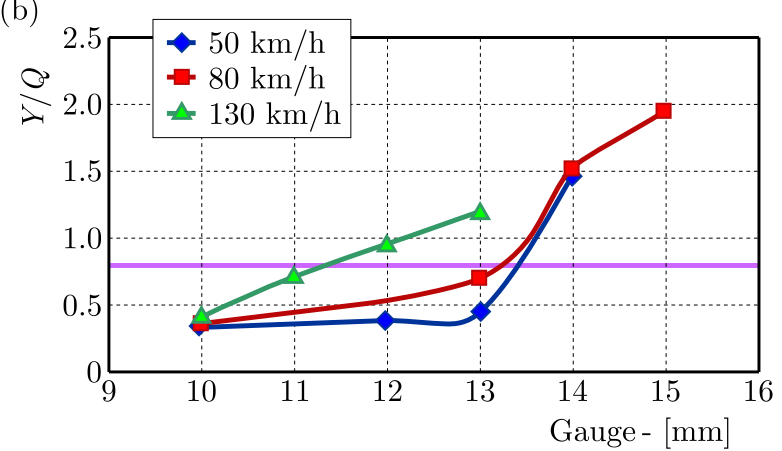

Fig. 8. Derailment index versus (a) extra gauge irregularity and (b) gauge shortage irregularity for speeds of 50,80 , and $140 \mathrm{~km} / \mathrm{h}$ 


\section{Investigating the effects of twist}

To model the twist irregularity, sinusoidal waves with amplitudes of 1,2 and $3 \mathrm{~mm}$ and wavelengths of 2-6 $\mathrm{mm}$ are used. The results of dynamical analysis of the modeled tracks with twist defects are presented in Figs. 9a to 9c. As these figures suggest, derailment is sensitive to both wavelength and amplitude of the twist. Keeping the amplitude constant, derailment occurs at shorter wavelengths. On the other hand, an increasing amplitude results in higher $Y / Q$ ratios. The twist with an amplitude of $3 \mathrm{~mm}$ results in derailment in speeds of 80 and $140 \mathrm{~km} / \mathrm{h}$ regardless of the wavelength, as shown in Fig. 9c. These results suggest that the twist is an influential parameter affecting derailment.

(a)

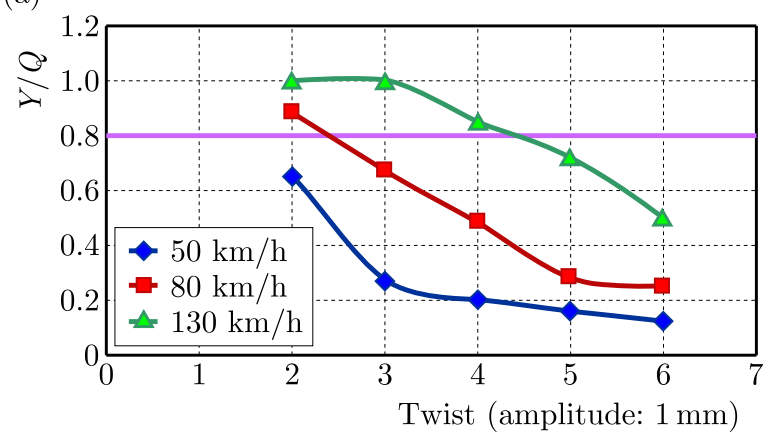

(b)

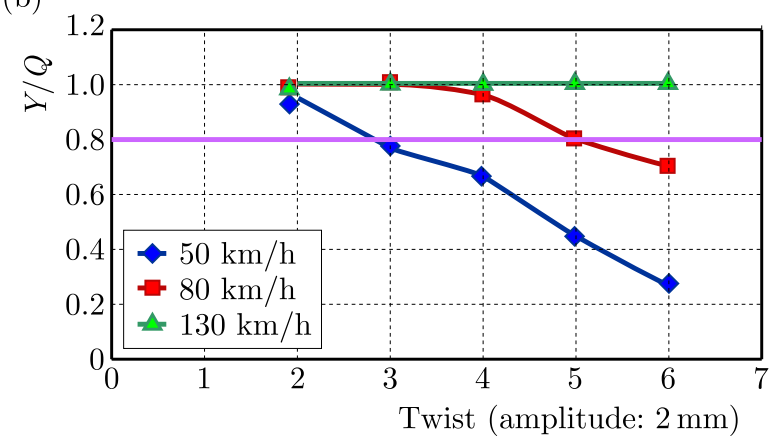

(c)

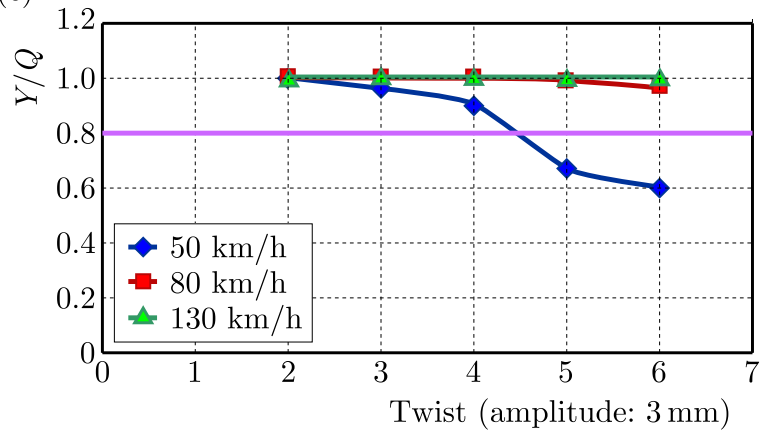

Fig. 9. Derailment index versus twist with an amplitude of (a) $1 \mathrm{~mm}$, (b) $2 \mathrm{~mm}$ and (c) $3 \mathrm{~mm}$ for speeds of 50,80 , and $140 \mathrm{~km} / \mathrm{h}$

\section{Comments on the results}

Critical amplitudes of track geometrical irregularities are concluded in Table 3 for speeds of 50,80 , and $140 \mathrm{~km} / \mathrm{h}$. Having the amplitude of track geometrical irregularities that result in derailment, thresholds could be developed by applying the safety factor to the values in Table 3 . Moreover, by dividing the critical values in Table 3 to the thresholds stated in the guidelines, it is possible to estimate the safety factors considered in the guidelines from the safety point of view. Figure 10 presents the safety factors determined for Iranian and Euro code standards. Alert limit state of Euro code is considered, since it is recommended based on safety issues related to derailment (EN-13848-5, 2008).

According to Fig. 10, Iranian standard is very conservative in defining thresholds since all safety factors are below 0.5, while Euro code considers logical safety factors. For example, Iranian standard considers a safety factor of 0.1 for the gauge shortage for a speed of $50 \mathrm{~km} / \mathrm{h}$, while this value is 0.8 in Euro Code standard. This shows that each standard considers a unique set of safety factors that depend on many parameters, such as the network in which it is applied, maintenance operations frequency and quality, rolling stock characteristics and operational regimes. Also, the 
Table 3. Critical values of geometrical irregularities that result in derailment

\begin{tabular}{|c|c|c|c|}
\hline \multirow{2}{*}{ Parameter } & \multicolumn{3}{|c|}{ Speed $[\mathrm{km} / \mathrm{h}]$} \\
\cline { 2 - 4 } & 50 & 80 & 140 \\
\hline \hline Alignment & 27 & 21 & 18 \\
\hline Profile & - & 150 & 40 \\
\hline Gauge + & 49.5 & 41 & 37 \\
\hline Gauge - & -13.5 & -13 & -11.5 \\
\hline Twist $(1 \mathrm{~mm})$ & - & 2.5 & 4.5 \\
\hline Twist $(2 \mathrm{~mm})$ & 3 & 5 & - \\
\hline Twist $(3 \mathrm{~mm})$ & 4.5 & - & - \\
\hline
\end{tabular}

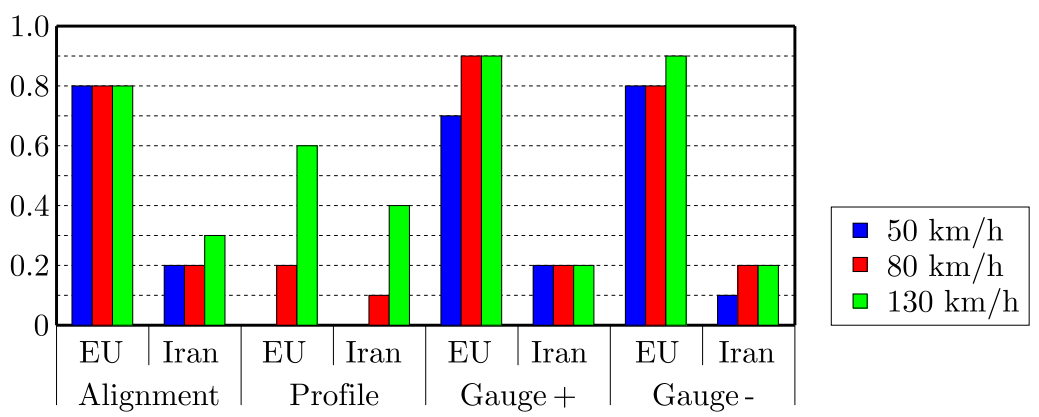

Fig. 10. Safety factors of Iranian and Euro code standard thresholds from the safety point of view

safety aspect is not the sole determinant of the thresholds, and restricted thresholds could be result from considering a plethora of factors for determining the thresholds.

According to Fig. 10, a single value is not considered as the safety factor for all geometrical parameters. For a speed of $140 \mathrm{~km} / \mathrm{h}$, safety factors for the alignment, vertical profile, extra gauge and shortage of gauge are 0.8, 0.6 and 0.9, respectively, according to Euro code. As expected, the safety factor of a geometrical parameter varies with speed as well. For example, Euro code takes safety factors of $0.8,0.6$, and 0.9 for the shortage of gauge irregularity at speeds of 50, 80, and 140 , respectively.

\section{Conclusion}

Track performance is highly dependent on the condition of geometrical parameters. Using a predefined set of thresholds, it is possible to monitor geometrical irregularities of the track and determine the quality index for a portion of the track. In this study, a method is proposed which could be used to select or define a new set of thresholds from the point of view of safety. To do so, geometrical irregularities are modeled in Adams/Rail finite element software and dynamical analyses are carried out to determine the derailment index. Varying the amplitude of geometrical irregularities, it is possible to determine the critical geometrical irregularity that results in derailment of the train.

The results suggest that derailment is highly correlated to twist and gauge shortage. According to the results, the twist with an amplitude of $3 \mathrm{~mm}$ results in derailment at speeds of 80 and $140 \mathrm{~km} / \mathrm{h}$ regardless of the wavelength. On the other hand, derailment is less sensitive to variations in the vertical profile irregularity, since no derailment occurs the vertical profile irregularity of $350 \mathrm{~mm}$ at a speed of $50 \mathrm{~km} / \mathrm{h}$.

Multiplying the critical values of track geometrical irregularities by safety factors, it is possible to develop a new set of thresholds from the safety aspect. The reverse could be done to 
determine safety factors of guidelines for developing thresholds, which is calculated in this paper for Euro code and Iranian standards. It is observed that each standard considers a unique set of safety factors to determine thresholds of geometrical irregularities. Iranian standard considers very restrictive safety factors, while Euro code choses a logical approach. This is mainly due to the fact that characteristics of the railway networks in which they are applied are different.

Considering high costs of maintenance operations and the importance of geometrical parameters to the safety of tracks, the selection of an optimized set of thresholds for a railway track is crucial. Using the proposed method of this paper could lead to an optimum set of thresholds that satisfies both financial and safety aspects at the same time. The same finite element model could also be used to determine the thresholds from any other aspect, such as ride comfort.

\section{References}

1. Amani J., Amini R., 2012, Prediction of shear strength of reinforced concrete beams using adaptive neuro-fuzzy inference system and artificial neural network, Scientica Iranica, DOI: 10.1016/j.scient.2012.02.009

2. Arasteh Khouy I., Larsson-Kråik P.O., Nissen A., Juntti U., Schunnesson H., 2013, Optimization of track geometry inspection interval, Journal of Rail and Rapid Transit, DOI: $10.1177 / 0954409713484711$

3. Arasteh Khouy I., Larsson-KrÅIK P.O., Nissen A., Kumar U., 2014, Cost-effective track geometry maintenance limits, Journal of Rail and Rapid Transit, 228, 5, 546-556

4. Ataei S., Mohammadzadeh S., Jadidi A., Miri A., 2014, Effects of maintenance operations on railway track's mechanical behavior by field load testing, International Journal of Pavement Engineering, 15, 3, 215-227

5. Berggren E.G., Li X.D.M., Spännar J., 2008, A new approach to the analysis and presentation of vertical track geometry quality and rail roughness, Wear, 265, 1488-1496, DOI: $10.1016 /$ j.wear.2008.01.029

6. Corrierea F., Di Vincenzo D., 2012, The rail quality index as an indicator of the „global comfort" in optimizing safety, quality and efficiency in railway rails, Procedia - Social and Behavioral Sciences, 53, 1090-1099, DOI: 10.1016/j.sbspro.2012.09.958

7. Elhag T.M.S., Boussabaine A.H., 2002, Tender price estimation using artificial neural network, II - Modeling, Journal of Financial Management of Property and Construction, 7, 1, 49-64

8. Elkins J., Wu H., 2000, New criteria for flange climb derailment, Proceedings of 2000 IEEE ASME Joint Rail-road Conference, Newark, NJ, April 4-6, DOI: 10.1109/RRCON.2000.869983

9. EN 14363, 2005, Railway Applications, Testing for the Acceptance of Running Characteristics of Railway Vehicles, Testing of Running Behaviour and Stationary Tests, CEN, Brussels

10. EN-13848-5, 2008, Track Geometry Quality, Geometric Quality Levels

11. Hong-Guang Ni., AND J.Z. WANG, 2000, Prediction of compressive strength of concrete by neural networks, Cement and Concrete Research, 30, 8, 1245-1250, DOI: 10.1016/S0008-8846(00)00345-8

12. Iran Ministry of Roads and Transportation, 2005, Railway Track Superstructure General Technical Specifications, Standard No. 301, Ministry Publication Service, pp. 9-12

13. JIN X.S., WEN Z.F., WANG K.Y., 2005, Effect of track irregularities on initiation and evolution of rail corrugation, Journal of Sound and Vibration, 285, 21-148, DOI: 10.1016/j.jsv.2004.08.042

14. Karmel A., Sweet L.M., 1981, Evaluation of time-duration dependent wheel load criteria for wheel climb derailment, ASME Journal of Dynamic Systems Measurement and Control, 103, 219-227, DOI: $10.1115 / 1.3140632$ 
15. Kik W., Menssen R., Moelle D., Bergerder B., 2002, Comparison of results of calculations and measurements of DYSAF-tests, A research project to investigate safety limits of derailment at high speeds, Vehicle System Dynamics, 37, Suppl., 543-553

16. Li D., Meddah A., Hass K., Kalay S., 2006, Relating track geometry to vehicle performance using neural network approach, Journal of Rail and Rapid Transit, 220

17. Madejski J., Grabczyk J., 2002, Continuous geometry measurement for diagnostics of track and switches, Proceedings of the International Conference on Switches, Delft University of Technology, Delft, The Netherlands

18. Miri A., Mohammadzadeh S., 2014, Acceleration-based quality assessment of railway tracks using a 2D simulation model and recorded track data, Advances in Railway Engineering, 2, 1, $13-20$

19. Mohammadzadeh S., Ghahremani S., 2010, Estimation of train derailment probability using rail vertical profile alterations, Structure and Infrastructure Engineering, 1-20, iFirst article alterations, DOI: $10.1080 / 15732479.2010 .500670$

20. Mohammadzadeh S., Sangtarashin M., Molatefi H., 2011, A novel method to estimate derailment probability due to track geometric irregularities using reliability techniques and advanced simulation methods, Archive of Applied Mechanics, 81, 1621-1637, DOI: 10.1007/s00419-011-0506-3

21. Nadal M.J., 1908, Locomotives à Vapeur, Collection Encyclopédie Scientifique, Bibliotèque de Mécanique Appliquée et Génie, vol. 186, Paris

22. ORE - International Union of Railways, (1981), Quantitative Evaluation of Geometric Track Parameters Determining Vehicle Behavior, Office of research and experiments, C152, RP1

23. Sibaie M.El., Jamieson D., Tyrell D., Dorcey J., Mee B., Whutten B., Kesler K., 1997, Engineering studies in support of the development of high speed track geometry specifications, IEEE/ASME Joint Railroad Conference, Boston, Massachusetts

24. Song H., KWON S., 2009, Evaluation of chloride penetration in high performance concrete using neural network algorithm and micropore structure, Cement and Concrete Research, 39, 9, 814-824, DOI: 10.1016/j.cemconres., 05.013

25. Union Internationale des CheminsdeFer, 2003, UIC CODE518, Sec.10-1-1-1, Second edition

26. Weinstock H., 1984, Wheel-climb derailment criteria for evaluation of rail vehicle safety, $A S M E$ Winter Annual Meeting, Paper No. 84-WA/RT-1

27. White H., 1989, Some asymptotic results for learning in single hidden layer feed forward network models, Journal of the American Statistical Association, 84, 408, 1003-1012, DOI: $10.1080 / 01621459,1989.10478$

28. Wu H., Wilson N., 2006, Railway vehicle derailment and prevention, [In:] Handbook of Railway Vehicle Dynamics, S. Inwicki (Edit.), 209-238. Taylor \& Francis, UK

29. Xia F., True H., 2004, The dynamics of the three-piece-freight truck, Vehicle System Dynamics, 41, 212-221, DOI: 10.1109/RRCON.2003.1204661

30. YADAV R.K., 2007, The Investigation of Derailments, 3rd ed., Indian Railways Institute of Civil Engineering 